\title{
Ana Enriqueta Terán o el corazón del águila'
}

\author{
JOSÉ CARLOS DE NÓBREGA* \\ Narrador y ensayista \\ Venezuela
}

(Recibido 24-06-20I4; aceptado 24-o6-2014)

Quién dïo que todo está perdido: / yo vengo a ofrecer mi corazón.

Fito Páez.

Las cuatro juntas: cómo ir contra el clan, aceptaron destino.

Ana Enriqueta Terán.

Apuntes y congojas de una decadencia novelada en tres muertes (2014) de Doña Ana Enriqueta Terán, primera incursión novelística publicada por la Fundación Editorial El perro y la rana, nos obsequió una experiencia inigualable y harto placentera: El discurso narrativo excede la historia del clan familiar e incluso la reivindicación de la voz femenina; su tersa y franca urdimbre está enclavada en la celebración conmovedora del habla de la infancia y el lenguaje poético que construye túneles de amor y memoria. Esta maravillosa novela coquetea, por fortuna, con la musicalidad clásica del soneto y la oralidad popular, rural y andina de la décima. La palabra recrea así nomás mestizajes alambicados y entrañables, eso sí, en el predatorio y dinámico marco de las relaciones de poder que encabritan a los hombres. Si bien no sólo hay alusiones autobiográficas sino también al devenir mismo de su obra poética (léase, por ejemplo, en voz alta el poema "Lo sagrado del sueño"), la novela nos parece uno de los mejores ejercicios de ficción literaria de los últimos treinta años en el país. Son abundantes sus virtudes narrativas que redundan en la calidad plástica y sinestésica de sus atmósferas, la construcción apasionada de los personajes y las modulaciones múltiples de la voz que cuenta y canta hasta cien para desandar o revisitar un siglo. Paradójicamente, autores como Gabriel García Márquez o Adriano González León cierran el ciclo con libros sobre la depreciación nostálgica de la

\footnotetext{
${ }^{\text {I }}$ Para citar este artículo: De Nóbrega, José Carlos (20I4). Ana Enriqueta Terán o el corazón del águila. Alabe 9 [www.revistaalabe.com]
} 
vejez; en cambio, Doña Ana intenta la senda inversa, esto es la recuperación poética de la infancia que trasciende la Utopía romántica (se trata de la consolidación de una voz singular cargada de humanidad tocable).

Las protagonistas son indudablemente maravillosas en la precariedad, la contrariedad, la fortaleza y los silencios de afuera y de adentro: Doña Juana Teresa, la abuela y la casa; Ama Ina, la sierva devota y celestina; y, por supuesto, Manuela, Isabel María, Niña Chayo, y Niña Candela, nietas y cuentas preciosas del rosario familiar contingente que se reconcilia con los anillos de la sierpe que pende de la viga principal del techo. Panchita, la culebra tuquí, no encarna la culpabilidad veterotestamentaria de la mujer infligida por el macho semental y patriarca, ni muerde su calcañar, por el contrario, las acompaña en las lazadas cómplices viga a viga (tal es el solidario cariz cenital de la voz narrativa que las enaltece, en el decir dubitativo y provocativo de Manuela, que reduce a los hombres temidos, amados, castrados y manipulados a emulsiones fantasmagóricas). El mea culpa tampoco funciona a nivel socio-económico, pues cunde la humanidad inmediata de godos y campesinos, niñas mantuanas y guarichas: “¿A ras de quién establecer culpas? Eran circunstancias. Intensos momentos en extensión de paño interno". He aquí la hermosísima irrupción del Bestiario, factor poético y metafórico de primer orden que afinca la compleja, sentida y escurridiza personalidad de cada quien, "el goce del tacto era el acercamiento a la bestia de uno": el escudo matriarcal encarnado en el águila de Doña Juana Teresa, encadenadas ambas en la casa; el cordero de Isabel María, "agobiado de blancura mística"; o el coleccionismo entomológico de Niña Chayo que se apropió no sólo de coleópteros y escarabajos, sino de otros animales y seres humanos amados. Se nos hace difícil no asociar la novela con dos obras maestras del cine: Gritos y Susurros de Ingmar Bergman, un evangelio coral feminista a cuatro voces, y Cría Cuervos de Carlos Saura que edifica un delicioso y complejo universo femenino en el opresivo confinamiento de la mansión burguesa poco antes de la muerte del franquismo. Por supuesto, nuestras mujeres se oponen sutil y silenciosamente al conservadurismo seco de la sociedad andina de aquel entonces: el "PURO LEER" de la matriarca, desde los clásicos rusos al Siglo de Oro español; pasando por la depredación sexual de Niña Candela o el ateísmo encubierto en la compulsiva religiosidad de Niña Chayo; hasta el dolorosísimo y vindicador ejercicio escritural de Manuela, desprovista de toda Victoria posible, “Será la palabra la única victoria de Manuela?" (qué tal les parece este llamado interior: “Despacito, Manuela, no se desboque; prados de hoja menuda no destruya", sazonado con la musicalidad inherente de un verso de arte mayor).

Si nos pidiesen llevar textos narrativos de nuestra predilección al Ágora o, mejor aún, a un espacio público más bondadoso, seleccionaríamos entre otros títulos “Acento de Cabalgadura" de Enrique Mujica, "En virtud de los favores recibidos" y "Los días mayores" de Orlando Chirinos, además de esta novela de Ana Enriqueta Terán. Privaría en esta arbitraria y sentida escogencia una concepción lúdica y transgenérica de la nove- 
lística y la cuentística, amén de la conjunción de la memoria y la oralidad como propuesta poética transparente e inmediata. Reiteramos que el lenguaje, en sus diversas implicaciones, es la línea central e indagatoria de Apuntes y congojas de una decadencia novelada en tres muertes. Constituye por una parte la revisión y recapitulación de la pasión escritural de nuestra autora. Son evidentes los puentes que establece con la Autobiografía en tercetos... de 2007 , especialmente en los casos de "Invocación a la madre" y "Ríos de infancia"; asimismo con la Antología poética de 2005, lo cual comprende la afinidad temática y las peculiaridades musicales e imaginativas de su discurso vital y personalísimo. Más importante aún, hemos de destacar el afán multidisciplinario que repercute hondamente en la construcción de este microcosmos novelístico: la prosa es olorosa al fogón de Ama Ina y al jardín cuidado por el infértil Juan Carlos Macchi; el discurso científico botánico y zoológico es motivo de apropiación y reconversión poéticas de la tierra y el paisaje; la condición de mujer se expone con bella crudeza comadrona y sin concesiones estilísticas: "Qué significa sangre menstrual en trapos viejos, (...), como si la sangre necesitara símbolos de poder, de tradición, para el holocausto de la inocencia y el suceso inaudito de la belleza". Los recovecos del habla que mixturan lo culto y lo popular no sólo recobran viejos términos, sino que imponen al cuerpo y el alma significados inéditos y juguetones: “Todos recuperaban el habla. 'Pasó un ángel', no sería mejor: 'pasó un demonio" “. La lengua absuelta por el vuelo y el reptar poético, nos mueve al morbo y al voyeurismo cuando de espejos se trata: la mirada oblicua que se desparrama en el pie equino de Isabel María (acariciado por Cheo Castejón o el mismísimo lector) o la desnudez virginal de Niña Chayo. La ceremonia transcurre entre la mascarada y la deglución caníbal del objeto luminoso del deseo, digresión sensual mediante.

Excusen, pues, el entusiasmo de estas notas dispersas y enamoradas, que celebran a nuestra queridísima Ana Enriqueta en su cumpleaños pleno de mocedades.

En Valencia, Rosa Única de Doña Ana, domingo 4 de mayo de 2OI4. 